\title{
A COUNTEREXAMPLE TO A QUESTION OF BAPAT \& SUNDER
}

\section{STEPHEN DRURY}

Abstract. The objective of this article is to provide a counterexample to a question of Bapat and Sunder concerning the relative magnitudes of the permanent of a positive semidefinite matrix and the largest eigenvalue of a related matrix. We also discuss the significance of this result in connection with the eigenvalues of the Schur matrix.

Mathematics subject classification (2010): 15A15.

Keywords and phrases: Permanent, Hadamard product, Oppenheim's inequality, permanent on top.

\section{REFERENCES}

[1] R. B. BAPAT, V. S. Sunder, On majorization and Schur products, Linear Algebra Appl. 72 (1985), $107-117$.

[2] R. B. BAPAT, V. S. SUNDER, An extremal property of the permanent and the determinant, Linear Algebra Appl. 76 (1986), 153-163.

[3] S. W. DruRY, A Counterexample to a Question of Bapat and Sunder, Electronic Journal of Linear Algebra 31 (2016), 69-70.

[4] S. W. DRURY, A real counterexample to two inequalities involving permanents, Mathematical Inequalities and Applications 20 (2017), 349-352.

[5] C. F. DunkL, D. E. Ramirez, Topics in harmonic analysis, Appleton-Century-Crofts, New York, 1971.

[6] G. D. James, The Representation Theory of Symmetric Groups, Lecture Notes in Mathematics, vol. 682, Springer-Verlag, New York, 1978.

[7] H. Minc, Theory of permanents 1978-1981, Linear Multilinear Algebra 12 (1983), 227-263.

[8] B. E. SAGAn, The Symmetric Group, Wadsworth \& Brooks/Cole, Pacific Grove, 1991.

[9] V. S. SHCHESNOVICH, The permanent-on-top conjecture is false, Linear Algebra Appl. 490 (2016), 196-201.

[10] G. Soules, Matrix functions and the Laplace expension theorem, Ph. D. Dissertation, University of California - Santa Barbara, July, 1966.

[11] F. ZHANG, An update on a few permanent conjectures, Special Matrices 4 (2016), 305-316. 